\title{
OSCILAÇÃO DO NÍVEL DE ÁGUA E A CO-OSCILAÇÃO DA MARÉ ASTRONÔMICA NO BAIXO ESTUÁRIO DO RIO PARAÍBA DO SUL, RJ
}

\author{
Micaela Nicolite ${ }^{1}$, Eliane Cristina Truccolo², \\ Carlos Augusto França Schettini ${ }^{3}$ e Carlos Eduardo Veiga de Carvalho ${ }^{4}$ \\ Recebido em 26 março, 2009 / Aceito em 31 agosto, 2009 \\ Received on March 26, 2009 / Accepted on August 31, 2009
}

\begin{abstract}
The water level in the lower Paraiba do Sul river estuary was assessed in order to evaluate the effects of the astronomical tide co-oscillation, river discharge and meteorological events. Water level data was recorded hourly from October 2000 until February 2003 at a gauge station nearby the estuarine inlet. The water level is controlled mainly by the astronomical tide co-oscillation during periods of low river discharge, and eventually by meteorological tides. Even during periods of higher river discharge the water level is controlled by astronomical co-oscillation, although during low tide phase the river discharge effects are observable. During periods of extreme high discharge the low frequency water level is mainly driven by the river inflow. The tidal wave was mostly symmetrical during the low river discharge periods, and asymmetries were observed during meteorological events, with shorter flood and longer ebbs. Although, such effects were not corroborated by astronomical tidal constituents $M_{2}$ and $M_{4}$ relationship, which suggests ebb dominance. Stronger distortions were observed during high discharge periods, with tide attenuation either at neap as in spring tide periods. During these periods the asymmetries were corroborated by $\mathrm{M}_{2}$ and $\mathrm{M}_{4}$ relationship.
\end{abstract}

Keywords: tidal asymmetry, meteorological tides, river discharge.

RESUMO. A variabilidade do nível da água no baixo estuário do rio Paraíba do Sul foi estudada para avaliar os efeitos da co-oscilação da maré astronômica, descarga fluvial e de eventos meteorológicos. Dados de nível da água foram registrados em intervalos horários para o período entre outubro de 2000 até fevereiro de 2003 em uma estação localizada próximo à desembocadura do estuário. Foi observado que durante os eventos de descarga fluvial baixa os níveis de água do estuário oscilam principalmente em função da co-oscilação da maré astronômica e eventualmente por marés meteorológicas. Durante períodos de descarga fluvial alta o nível da água de preamar no baixo estuário é dominado pela co-oscilação, enquanto que nas baixa-mares é influenciado pela descarga fluvial. Em períodos de descarga fluvial muito alta o estuário passa a receber a influência tanto da descarga fluvial quanto da maré astronômica nas oscilações do nível. Em períodos de baixa descarga quase não houve modificação na onda de maré, sendo observada pequena assimetria no sentido de vazante. Ainda em baixa descarga, eventos de maré meteorológica produzem distorções e assimetrias, com o tempo de subida menor que o de descida, gerando correntes mais fortes no sentido de enchente. Contudo, isto não pôde ser confirmado com a relação de fase entre $\mathrm{M}_{2}$ e $\mathrm{M}_{4}$, que sugeriu domínio de vazante. A descarga fluvial alta causou fortes distorções na onda de maré em períodos de quadratura e uma atenuação considerável nas amplitudes tanto de sizígia como de quadratura, com assimetrias no sentido de vazante corroboradas pela relação de fase entre $\mathrm{M}_{2}$ e $\mathrm{M}_{4}$

Palavras-chave: assimetria de maré, marés meteorológicas, descarga fluvial.

\footnotetext{
${ }^{1}$ Laboratório de Ciências Ambientais, Centro de Biociências e Biotecnologia, Universidade Estadual do Norte Fluminense, LCA/UENF, Av. Alberto Lamego, 2000, Pq. Califórnia, 28013-602 Campos dos Goytacazes, RJ, Brasil. Telefax: +55(22) 2739-7032 - E-mail: micaela_uenf@yahoo.com.br

2 Programa de Pós-Graduação em Geociências, Universidade Federal do Rio Grande do Sul, PPGGeo/UFRGS, CP 15001, 91509-900 Porto Alegre, RS, Brasil. Tel.: +55(51) 3308-6340; Fax: +55(51) 3308-6332 -E-mail: nane.truccolo@gmail.com

3 Instituto de Ciências do Mar, Universidade Federal do Ceará, LABOMAR/UFC, Av. da Abolição, 458, Centro, CP 360, 60165-081 Fortaleza, CE, Brasil. Tel.: +55(85) 3366-7023; Fax: +55(85) 3366-7002 - E-mail: guto.schettini@gmail.com

${ }^{4}$ Laboratório de Ciências Ambientais, Centro de Biociências e Biotecnologia, Universidade Estadual do Norte Fluminense, LCA/UENF, Av. Alberto Lamego, 2000, Pq. Califórnia, 28013-602 Campos dos Goytacazes, RJ, Brasil. Tel.: +55(22) 2726-1403; Fax: +55(22) 2726-1472 - E-mail: carvalho@uenf.br
} 


\section{INTRODUÇÃo}

Um sistema estuarino apresenta variações na sua hidrodinâmica induzidas por processos marinhos e fluviais. Na porção marinha, a circulação da plataforma adjacente influencia a dinâmica estuarina através de forçantes como as ondas de marés astronômicas, marés meteorológicas, de plataforma e ondas de gravidade. Enquanto que na porção fluvial há o predomínio da descarga de água doce (Parker, 1991; Pugh, 2004). Os movimentos verticais que ocorrem em períodos de marés astronômicas são denominados de mareais ou freqüência mareal (FM), da ordem de horas a dezenas de horas. Os movimentos que ocorrem em períodos menores são chamados de oscilações de freqüência supramareal (FSupM), da ordem de dezenas de minutos como oscilações de seiches e tsunamis. Os movimentos com períodos maiores que 0 da maré astronômica são denominados de freqüência submareal (FSubM), tal como a descarga fluvial, inclinação da superfície da água ao longo do estuário, ondas de marés meteorológicas e de plataforma (Miranda et al., 2002; Truccolo, 2005). Os processos em FM, FSubM e FSupM atuam de forma diferenciada, alterando o padrão de movimento da água e todo o material que está sendo transportado pelas correntes ao longo do estuário.

As marés oceânicas podem sofrer distorções em suas amplitudes e modificação na fase durante sua progressão no sentido de águas rasas e ambientes restritos como baías e estuários. Estas alterações são devido ao atrito com o fundo; à compressão das margens do canal; à configuração da costa que direciona 0 fluxo de marés, e à profundidade do canal estuarino. Além das alterações acima citadas, perturbações hidrológicas e meteorológicas também são responsáveis por distorções no padrão da onda de co-oscilação da maré astronômica (George, 1995; Dyer, 1997; Pugh, 2004). A distorção é causada pela interação não linear dos principais constituintes harmônicos de maré em águas rasas, gerando novos harmônicos de maré com freqüências maiores além de assimetrias de fase e na forma da maré (Speer \& Aubrey, 1985; Parker, 1991; George, 1995; Truccolo, 2005). 0 tempo de assimetria desenvolvida entre a subida e a descida da onda de maré pode ser representado pelo crescimento não-linear dos principais constituintes harmônicos da maré astronômica, podendo ser observado empiricamente através de registros de nível da água ao longo de estuários (Truccolo \& Schettini, 1999; Mao et al., 2004).

Além dos termos friccionais e de águas rasas, as interações entre os constituintes astronômicos de maré, entre estes e a descarga fluvial e também a interação com as flutuações em FSubM de origem meteorológica são responsáveis pela variação da al- tura da co-oscilação da maré astronômica (Parker, 1991). Há uma relação intrínseca entre a fricção, descarga fluvial e co-oscilação da maré, pois a fricção é sentida somente onde existem correntes. A descarga fluvial determinará a sucessão de correntes que prevalecerão num ciclo de maré, portanto, a distorção gerada na co-oscilação da maré se dará em função da variabilidade do fluxo fluvial (Truccolo, 2005).

Embora tipologicamente o rio Paraíba do Sul deságüe num sistema deltaico dominado por ondas, o seu trecho inferior consiste de um estuário onde ocorre mistura de águas fluviais e marinhas (Krüger et al., 2003). 0 estuário do rio Paraíba do Sul é dominado pela descarga fluvial, porém em períodos de baixa descarga ocorre a entrada de águas marinhas, e os processos de transporte de escalares passam a ser regidos pelas marés. 0 objetivo do presente trabalho é 0 de avaliar as oscilações em freqüência mareal (FM) do nível de água do baixo estuário do rio Paraíba do Sul, próximo à barra em Atafona, relativo à co-oscilação da maré astronômica e a influência das oscilações em freqüência submareal (FSubM), tais como as marés meteorológicas costeiras e a descarga fluvial, na propagação da cooscilação da maré.

\section{Área de estudo}

A Bacia do Rio Paraíba do Sul (RPS) localiza-se entre os paraleIos $20^{\circ} 26^{\prime}$ e $23^{\circ} 38^{\prime}$ Sul e os meridianos de $41^{\circ}$ e $46^{\circ} 39^{\prime}$ Oeste com área total de $55.400 \mathrm{~km}^{2}$ e extensão aproximada de $1145 \mathrm{~km}$. Está inteiramente inserida dentro da região Sudeste do Brasil e diretamente relacionada ao maior centro de produção e consumo do país, que compreende os estados de Minas Gerais, São Paulo e Rio de Janeiro (Carneiro, 1998) (Fig. 1).

A desembocadura do RPS é caracterizada por depósitos sedimentares encontrados em duas regiões geomorfológicas típicas: a) Planícies Costeiras e Modelados de Acumulação Fluvial e b) Tabuleiro Costeiro. A Planície costeira que se desenvolve na embocadura do rio é de origem sedimentar quaternária, constituída por terraços marinhos arenosos de idade pleistocênica, com sedimentos lagunares e fluviais de idade holocênica (Martin et al., 1984).

0 regime pluviométrico é bem caracterizado. No período de novembro a janeiro tem-se o trimestre mais chuvoso da região, provocando grandes cheias no RPS. Estas afetam mais a região do trecho inferior do rio, principalmente a planície Campista e de São João da Barra onde os transbordamentos ocorrem com mais freqüência. 0 período de junho a agosto é o mais seco, ocorrendo vazões mínimas médias em torno de $200 \mathrm{~m}^{3} . \mathrm{s}^{-1}$ em Campos dos Goytacazes. Segundo Costa (1994) houve um decréscimo de 


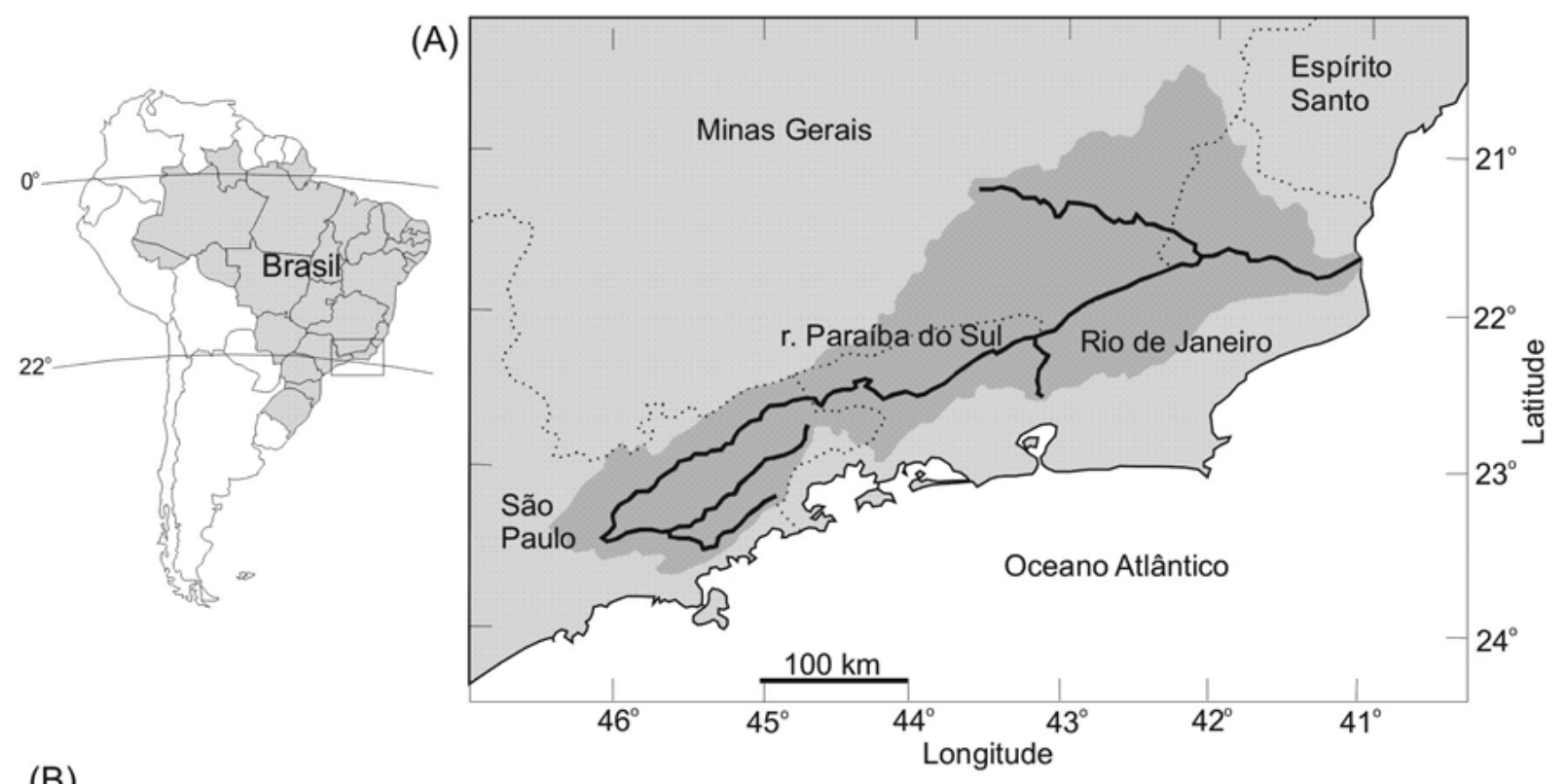

(B)

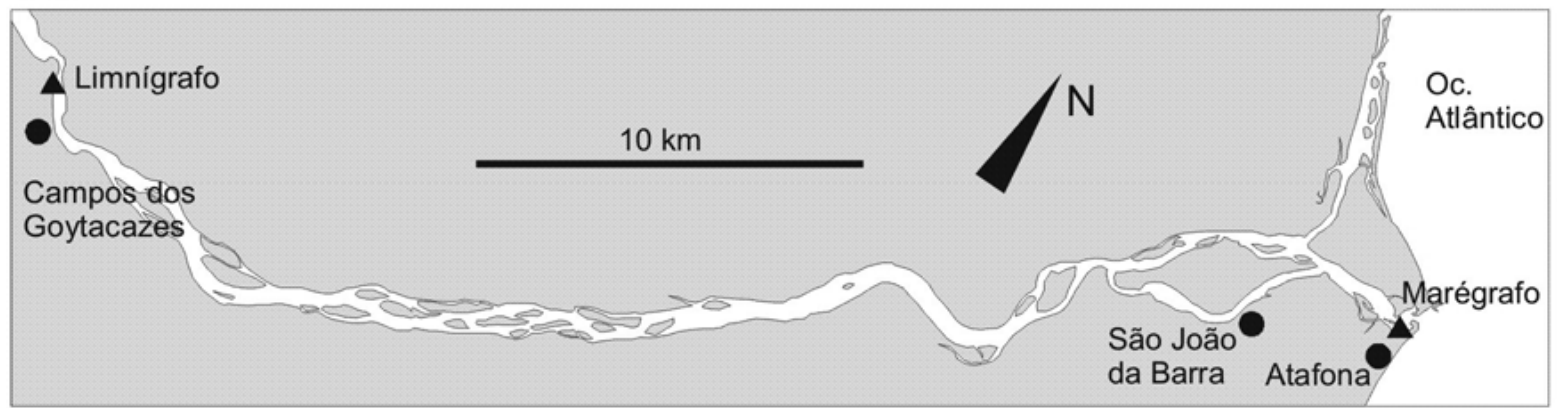

Figura 1 - (A) Bacia Hidrográfica do Rio Paraíba do Sul, e (B) 0 trecho entre Campos dos Goytacazes e Atafona, com a localização do marégrafo e do limnígrafo.

cerca de 50\% nos valores de vazão mínima a partir da segunda metade da década de 50, perdurando até a década de 80 . Esta diminuição foi atribuída a diversos empreendimentos hidráulicos, especialmente hidrelétricos, executados no RPS neste período.

0 curso inferior do RPS é 0 trecho da bacia entre a cidade de Itaocara e a desembocadura, na cidade de Atafona, distrito de São João da Barra, RJ. 0 sistema estuarino do RPS é complexo em termos fisiográficos. Em resposta aos níveis de energia fluvial e suprimento sedimentar, encontram-se inúmeras ilhas e uma saída principal ao sul, em Atafona (Fig. 1).

Observa-se, nos últimos 50 anos, que a praia de Atafona vem sofrendo um gradativo processo de erosão (retrogradação) que se estende por um trecho de aproximadamente $4 \mathrm{~km}$, com a destruição do seu pontal e, conseqüente progradação nas praias de Grussaí, localizadas ao sul. As condições ambientais predominantes nas décadas passadas são ainda desconhecidas, mas há os agentes fluvial e marinho presentes com influência marcante da ação de ondas e da variação hidrodinâmica do rio (Ribeiro \& Rosas, 2006).

\section{METODOLOGIA}

Dados de nível da água foram registrados com um marégrafo de pressão marca OTT-Hydrometrie, modelo Orphimedes, com sistema digital de medição para fornecer registros horários de nível de água. 0 marégrafo foi instalado no dia 24 de outubro de 2000 à montante da barra do estuário do rio Paraíba do Sul, na latitude $21^{\circ} 22^{\prime}$ S e longitude $41^{\circ} 00^{\prime}$ W (Fig. 1). Os registros de pressão hidrostática, já corrigidos os valores de pressão atmostérica, foram adquiridos com intervalo amostral de 20 minutos, sendo convertidos em valores de níveis horários médios para o período de 24 de outubro de 2000 até 28 de fevereiro de 2003.

Para a obtenção do nível de água do estuário em FSubM, relativo aos efeitos do nível do mar costeiro e descarga fluvial, as séries passaram por um processo de filtragem onde foi ex- 
traído o nível de água em baixa freqüência. 0 filtro utilizado foi 0 filtro quadrático de Lanczos, com corte de freqüência de 40 horas, que elimina 60 dados no início e 60 dados no final da série (Truccolo et al., 2006). As alturas da co-oscilação da maré astronômica observada foram obtidas pela diferença entre 0 nível de água estuarino e o nível filtrado.

Foi realizada uma análise de variância no domínio do tempo do nível de água estuarino. Posteriormente, no domínio da freqüência foi feita uma análise espectral que estima a variância em faixas ou bandas de freqüência. 0 espectro de variância da maré oferece um entendimento dos processos que afetam esse componente dinâmico das oscilações do nível de água estuarino.

Dados diários de descarga fluvial para os anos de 1934 a 2006 foram obtidos junto à Agência Nacional de Águas (ANA) para a estação limnimétrica localizada no município de Campos dos Goytacazes, RJ, à aproximadamente $40 \mathrm{~km}$ da desembocadura do estuário (Fig. 1). No presente estudo foram definidos como períodos de alta descarga fluvial os valores acima da média histórica e como baixa descarga valores inferiores a média histórica.

\section{Análise harmônica}

Os principais constituintes harmônicos (ex: $\mathrm{O}_{1}$ e $\mathrm{M}_{2}$ ), componentes (ex: $\mathrm{M}_{4}$ ) e compostos (ex: $\mathrm{MS}_{4}$ ) de maré, e conseqüentemente a previsão das alturas da co-0scilação da maré astronômica foram obtidos através do método harmônico utilizando o programa PACMARE (Previsão e Análise de Maré) desenvolvido por Franco (1988). 0 objetivo desta análise é extrair as amplitudes e fases dos principais constituintes de maré a partir de registros do nível de água. A análise é baseada na análise de Fourier e foi desenvolvida por Schureman (1971).

A partir das séries temporais de nível e vazão, foram selecionados períodos de 29 dias para determinação de constituintes harmônicos de maré e analise dos efeitos não lineares sobre 0 nível da água. Foram selecionados três períodos de baixa descarga (BD1, 2 e 3), três períodos de alta descarga (AD1, 2 e 3), e três períodos de baixa descarga durante os quais ocorreram algum evento meteorológico expressivo (MM1, 2 e 3). Por evento meteorológico expressivo, foi considerada uma oscilação do sinal em FSubM maior do que $30 \mathrm{~cm}$. Os períodos selecionados e a descarga fluvial média para cada período são apresentados na Tabela 1. As séries temporais de nível da água registrado no estuário e de descarga fluvial para os períodos de baixa descarga, alta descarga, e baixa descarga com eventos de maré meteorológica são apresentadas nas Figuras 2, 3 e 4, respectivamente. Após a seleção, estas foram usadas nas análises harmônicas de maré descritas acima, para obtenção dos constituintes em períodos de variação da descarga fluvial. Da mesma forma foi feito para os períodos com maré meteorológica. Os níveis de cooscilação da maré astronômica observada foram cruzados com a maré astronômica prevista para toda a série, que foi obtida em um período de 29 dias com descarga fluvial média de $300 \mathrm{~m}^{3} \cdot \mathrm{s}^{-1}$.

\section{RESULTADOS}

Através da análise de variância do nível de água do estuário no domínio do tempo pôde-se verificar que as oscilações em FM representadas pela maré astronômica foram responsáveis por $83,6 \%$ da variabilidade do nível de água, enquanto que as oscilações em FSubM como a descarga fluvial e marés meteorológicas representaram cerca de 15\%, sendo 0 1,5\% restante devido às variações sazonais.

A análise dos dados de descarga diária de 1934 até 2003, fornece uma descarga média de $796 \pm 566 \mathrm{~m}^{3} . \mathrm{s}^{-1}$, com mínima de 118 e máxima de $8.376 \mathrm{~m}^{3} . \mathrm{s}^{-1}$, ocorrendo nos dias 29/09/1955 e 15/01/1966, respectivamente. A descarga média mensal, obtida entre os anos de 1934 e 2003 apresentou os picos de máxima descarga em janeiro, $1.463 \pm 577 \mathrm{~m}^{3} . \mathrm{s}^{-1}$, e em fevereiro, $1.410 \pm 420 \mathrm{~m}^{3} \cdot \mathrm{s}^{-1}$, e os picos de mínima em agosto, 389 $\pm 37 \mathrm{~m}^{3} \cdot \mathrm{s}^{-1}$, e setembro, $386 \pm 62 \mathrm{~m}^{3} \cdot \mathrm{s}^{-1}$ (Fig. 5). Há uma variação sazonal da descarga média mensal, com os períodos seco e chuvoso bem definidos, embora haja um desvio padrão alto no verão. Para o período de 2000 a 2003 foi obtida uma descarga diária média de $511 \pm 390 \mathrm{~m}^{3} . \mathrm{s}^{-1}$, com mínima de 177 e máxima de $3.284 \mathrm{~m}^{3} \cdot \mathrm{s}^{-1}$. Esta média é inferior a média histórica de $796 \mathrm{~m}^{3} \cdot \mathrm{s}^{-1}$.

As Tabelas 2, 3 e 4 apresentam os resultados da análise harmônica para determinação dos constituintes harmônicos da co-oscilação de maré para os períodos de baixa descarga (BD), alta descarga (AD) e baixa descarga com eventos meteorológicos, respectivamente. A Tabela 5 apresenta parâmetros descritores da maré astronômica e o somatório das amplitudes e porcentagem das constantes harmônicas em todos os períodos selecionados.

\section{Períodos de baixa descarga}

Um total de 14 constantes harmônicas estatisticamente significativas ao nível de $95 \%$ de confiança foi obtido para os três períodos de baixa descarga, sendo 4 de espécies diurnas e 5 semidiurnas comuns aos três períodos e um total de 5 constantes de águas rasas, sendo apenas o $M_{4}, M_{4}$ e $M_{6}$ comuns aos três períodos. 0 constituinte $\mathrm{M}_{4}$ é o mais expressivo dos componentes de águas rasas com 2,1 cm em média, em seguida o $\mathrm{M}_{6}$ e 0 composto $\mathrm{MS}_{4}$, 
Tabela 1 - Períodos selecionados da descarga fluvial e suas respectivas vazões médias para análise da co-oscilação da maré astronômica no baixo estuário do RPS.

\begin{tabular}{|c|c|c|c|c|}
\hline Condição & Períodos & Início & Término & $\begin{array}{c}\text { Vazão média } \\
\left(\mathrm{m}^{3} . s^{-1}\right)\end{array}$ \\
\hline \multirow{3}{*}{ Baixa descarga } & $\mathrm{BD} 1$ & $23 / 05 / 2001$ & $25 / 06 / 2001$ & 292 \\
\cline { 2 - 5 } & $\mathrm{BD2}$ & $25 / 06 / 2001$ & $23 / 07 / 2001$ & 223 \\
\cline { 2 - 5 } & $\mathrm{BD3}$ & $09 / 04 / 2002$ & $07 / 05 / 2002$ & 369 \\
\hline \multirow{3}{*}{ Alta descarga } & $\mathrm{AD} 1$ & $25 / 11 / 2000$ & $23 / 12 / 2000$ & 746 \\
\cline { 2 - 5 } & $\mathrm{AD2}$ & $12 / 12 / 2001$ & $09 / 01 / 2002$ & 943 \\
\cline { 2 - 5 } & $\mathrm{AD} 3$ & $24 / 01 / 2002$ & $21 / 02 / 2002$ & 1208 \\
\hline \multirow{2}{*}{$\begin{array}{c}\text { Baixa descarga } \\
\text { com maré } \\
\text { meteorológica }\end{array}$} & $\mathrm{MM1}$ & $02 / 07 / 2001$ & $30 / 07 / 2001$ & 252 \\
\cline { 2 - 5 } & $\mathrm{MM} 2$ & $05 / 08 / 2001$ & $02 / 09 / 2001$ & 192 \\
\cline { 2 - 5 } & $\mathrm{MM} 3$ & $21 / 09 / 2001$ & $19 / 10 / 2001$ & 217 \\
\hline
\end{tabular}
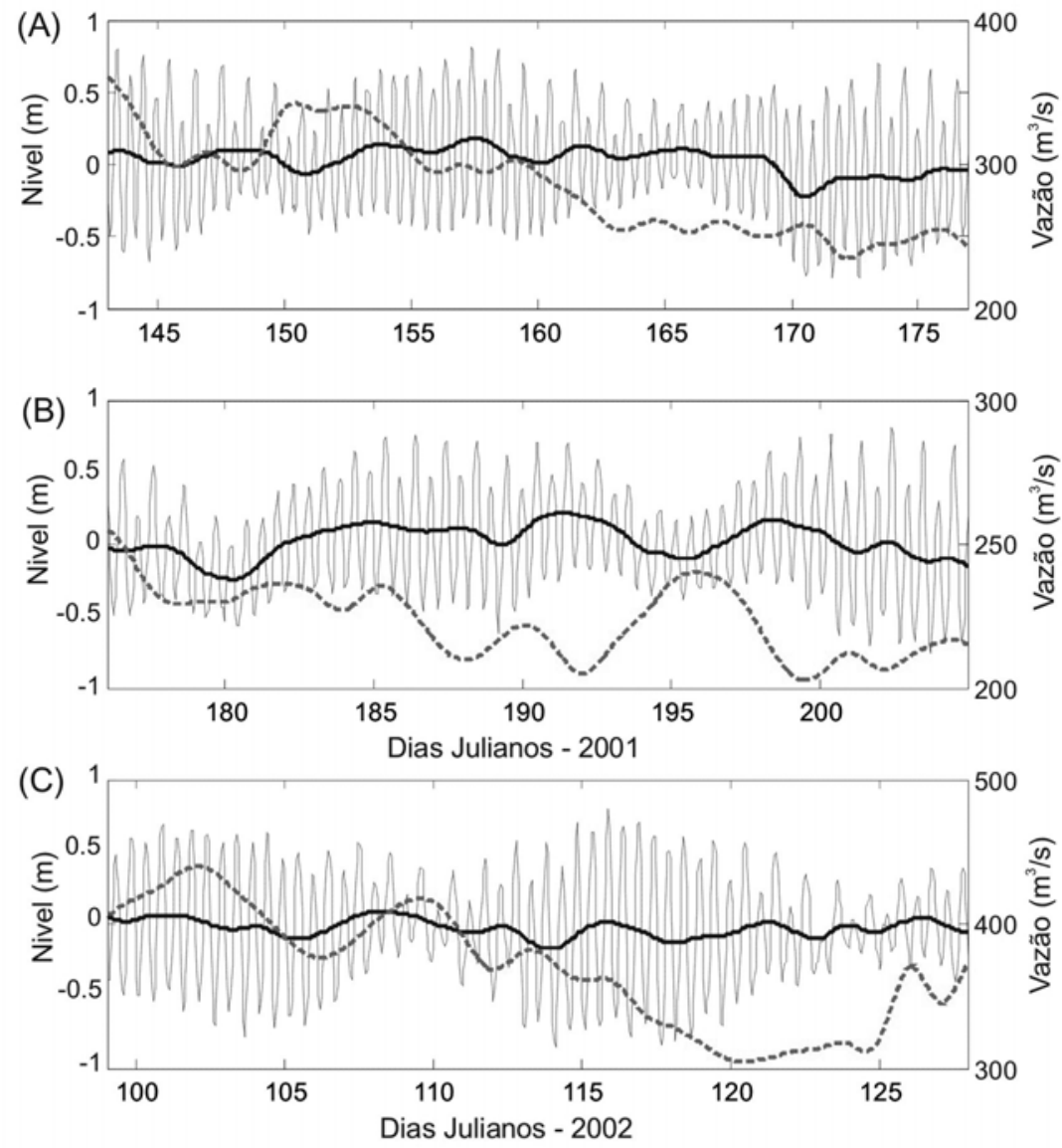

Figura 2 - Séries temporais de nível de água (linha cheia) e vazão (linha tracejada) dos períodos selecionados para caracterizar condição de baixa descarga do rio Paraíba do Sul. A: BD1; B: BD2; C: BD3. Detalhes na Tabela 1. A linha preta em negrito representa o nível da água em freqüência submareal.

ambos com média de $1,5 \mathrm{~cm}$. As constantes principal lunar $\mathrm{M}_{2}$ e principal solar $S_{2}$ são as mais energéticas, apresentando a primeira 43,0; 41,7 e $43,7 \mathrm{~cm}$ e a segunda 19,$4 ; 18,5$ e $21,1 \mathrm{~cm}$, respectivamente.
A altura média da maré encontrada nos três períodos de baixa descarga foi de 94,6; 91,7 e 96,1 cm, atingindo valores médios nas preamares de sizígia de 124,8; 120,3 e 129,6 cm e durante os períodos de baixa-mares de quadratura 47,2; 46,5 e 45,2 cm, 

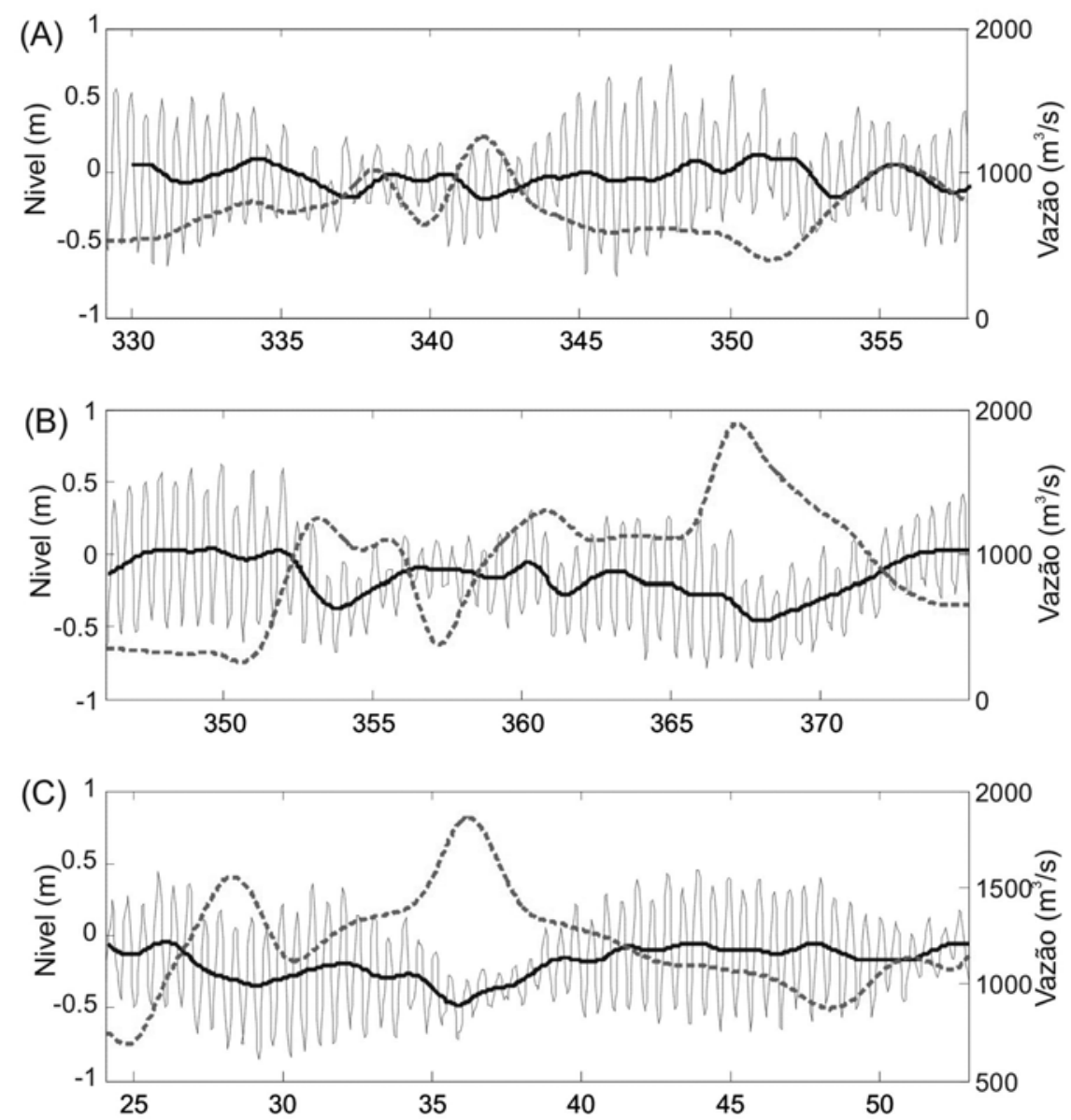

Figura 3 - Séries temporais de nível de água (linha cheia) e vazão (linha tracejada) dos períodos selecionados para caracterizar condição de alta descarga do rio Paraíba do Sul. A: AD1; AD2; AD3. Detalhes na Tabela 1. A linha preta em negrito representa o nível da água em freqüência submareal.

respectivamente. Desta forma, a região pode ser caracterizada por micro-marés, pois a altura máxima da maré em todos os períodos foi menor que $2 \mathrm{~m}$ (Tab. 5). A importância relativa das principais constantes de maré diurnas $\left(K_{1}\right.$ e $\left.0_{1}\right)$ e semidiurnas $\left(M_{2}\right.$ e $S_{2}$ ) pode ser avaliada pela razão de suas amplitudes através do Número de Forma. Os Números de Forma encontrados para os três períodos foram iguais a 0,$25 ; 0,25$ e 0,22 ; 0 que representa um regime de maré do tipo misto, predominantemente semidiurno, com desigualdades de alturas para as preamares e baixa-mares consecutivas. As constantes de espécies diurnas representam 19,7; 19,1 e 17,1\% do somatório das amplitudes. As constantes de espécies semidiurnas são responsáveis por 73,$1 ; 73,5$ e 76,8\% da energia de maré, sendo que os 7,2; 7,4 e 6,1\% restantes são devido às constantes de água rasa, respectivamente para os períodos 1,2 e 3.

Foram obtidas a razão $A \mathrm{M}_{4} / A \mathrm{M}_{2}$ e a relação de fase $\left(2 \theta \mathrm{M}_{2}\right.$ $-\theta \mathrm{M}_{4}$ ) que são os indicativos de distorção no sistema. Os resultados da razão das amplitudes encontrados para os três períodos foram iguais a 0,05 para BD1 e BD2, e 0,04 para BD3. Isto indica que a quarto-diurna representa apenas $5 \%$ da amplitude semidiurna. A relação de fase foi de $283,4^{\circ} ; 287,7^{\circ}$ e $293,8^{\circ}$, respectivamente para BD1, BD2 e BD3.

Em baixas descargas e constantes (menor que $370 \mathrm{~m}^{3} \cdot \mathrm{s}^{-1}$ ), a onda de co-oscilação da maré coincide com 0 nível previsto e apresenta um comportamento quase simétrico, com 0 tempo de subida muito próximo ao tempo de descida, porém com uma leve tendência para vazante. Para exemplificar, nos dias 4/06/01 (sizígia) e 14/06/01 (quadratura), 0 tempo de subida durou 7 horas, enquanto que 0 da descida durou 6h, porém na quadratura houve uma pequena distorção, conforme ilustrado na Figura 6. Isto sugere que nestes períodos de descarga baixa e constante, a variação do nível de água do baixo estuário é 
Tabela 2 - Constituintes harmônicos de maré para os períodos de baixa descarga (BD, Tab. 1) significativas ao nível de $95 \%$ de confiança, com suas respectivas amplitudes (cm) e fases (graus).

\begin{tabular}{|c|c|c|c|c|c|c|}
\hline \multirow{2}{*}{ Espécies } & \multicolumn{2}{|c|}{ BD1 } & \multicolumn{2}{c|}{ BD2 } & \multicolumn{2}{c|}{ BD3 } \\
\cline { 2 - 7 } & amplitude & fase & amplitude & fase & amplitude & fase \\
\hline Diurnas & \multicolumn{5}{|l|}{} \\
\hline$Q_{1}$ & 2,4 & 245,3 & 2,3 & 251,6 & 2,3 & 242,1 \\
\hline $0_{1}$ & 9,2 & 278,5 & 8,4 & 281,6 & 8,8 & 279,3 \\
\hline $\mathrm{K}_{1}$ & 6,5 & 334,0 & 6,6 & 332,6 & 5,7 & 318,5 \\
\hline $\mathrm{P}_{1}$ & 2,2 & 229,9 & 2,2 & 328,8 & 1,9 & 315,5 \\
\hline \hline Semidiurnas & \multicolumn{5}{|l|}{} \\
\hline $\mathrm{N}_{2}$ & 6,3 & 275,2 & 6,2 & 288,2 & 8,7 & 283,5 \\
\hline $\mathrm{M}_{2}$ & 43,0 & 269,7 & 41,7 & 270,1 & 43,7 & 266,4 \\
\hline $\mathrm{L}_{2}$ & 1,4 & 247,3 & 3,5 & 201,2 & 4,6 & 247,9 \\
\hline $\mathrm{S}_{2}$ & 19,4 & 284,9 & 18,5 & 286,0 & 21,1 & 272,3 \\
\hline $\mathrm{K}_{2}$ & 5,3 & 286,1 & 5,0 & 288,3 & 5,7 & 272,8 \\
\hline \hline Água rasa & \multicolumn{5}{|l|}{} \\
\hline $\mathrm{M}_{4}$ & 2,2 & 256,0 & 2,2 & 252,6 & 1,9 & 239,0 \\
\hline $\mathrm{MS}_{4}$ & 1,6 & 316,6 & 1,6 & 317,3 & 1,2 & 299,0 \\
\hline $\mathrm{MSN}_{2}$ & 2,2 & 258,5 & - & - & - & - \\
\hline $\mathrm{MU}_{2}$ & - & - & 2,5 & 276,7 & 1,8 & 268,4 \\
\hline $\mathrm{M}_{6}$ & 1,4 & 275,2 & 1,2 & 275,9 & 1,8 & 253,5 \\
\hline \hline Soma $^{2}$ & 103,1 & & 101,9 & & 109,2 & \\
\hline
\end{tabular}

Tabela 3 - Constituintes harmônicos de maré para os períodos de alta descarga (AD, Tab. 1) significativas ao nível de 95\% de confiança, com suas respectivas amplitudes (cm) e fases (graus).

\begin{tabular}{|c|c|c|c|c|c|c|}
\hline \multirow{2}{*}{ Espécies } & \multicolumn{2}{|c|}{ AD1 } & \multicolumn{2}{|c|}{ AD2 } & \multicolumn{2}{|c|}{ AD3 } \\
\hline & amplitude & fase & amplitude & fase & amplitude & fase \\
\hline \multicolumn{7}{|l|}{ Diurnas } \\
\hline $0_{1}$ & 6,6 & 279,8 & 7,3 & 281,2 & 6,2 & 278,8 \\
\hline$K_{1}$ & 3,9 & 5,0 & 2,6 & 343,6 & 2,3 & 351,4 \\
\hline \multicolumn{7}{|c|}{ Semidiurnas } \\
\hline$L_{2}$ & 5,3 & 156,7 & 4,4 & 198,0 & 3,5 & 240,4 \\
\hline$M_{2}$ & 34,3 & 276,7 & 34,4 & 267,6 & 34,1 & 262,6 \\
\hline $\mathrm{S}_{2}$ & 16,1 & 301,0 & 15,4 & 273,5 & 16,5 & 277,8 \\
\hline $\mathrm{N}_{2}$ & - & - & 3,1 & 232,6 & 4,9 & 296,2 \\
\hline $\mathrm{K}_{2}$ & 4,4 & 303,0 & 4,2 & 274,0 & 4,5 & 279,0 \\
\hline \multicolumn{7}{|l|}{ Água rasa } \\
\hline$M_{4}$ & 2,1 & 261,3 & 2,7 & 277,0 & 1,9 & 266,0 \\
\hline $\mathrm{MS}_{4}$ & 2,0 & 325,0 & 2,1 & 314,1 & 2,0 & 318,2 \\
\hline $\mathrm{MSN}_{2}$ & - & - & 2,5 & 21,7 & 2,0 & 75,1 \\
\hline$M_{6}$ & 1,8 & 276,1 & 2,0 & 266,7 & 1,6 & 249,5 \\
\hline Soma & 76,5 & & 80,7 & & 79,5 & \\
\hline
\end{tabular}


Tabela 4 - Constituintes harmônicos de maré para os períodos de baixa descarga com eventos de marés meteorológicas (MM, Tab. 1) significativas ao nível de 95\% de confiança, com suas respectivas amplitudes (cm) e fases (graus).

\begin{tabular}{|c|c|c|c|c|c|c|}
\hline \multirow{2}{*}{ Espécies } & \multicolumn{2}{|c|}{ MM1 } & \multicolumn{2}{|c|}{ MM2 } & \multicolumn{2}{|c|}{ MM3 } \\
\hline & amplitude & fase & amplitude & fase & amplitude & fase \\
\hline \multicolumn{7}{|l|}{ Diurnas } \\
\hline$Q_{1}$ & 1,6 & 240,3 & 1,8 & 247,0 & 3,0 & 261,4 \\
\hline $0_{1}$ & 8,7 & 194,5 & 7,3 & 291,6 & 7,5 & 289,1 \\
\hline$K_{1}$ & 6,2 & 346,4 & 7,6 & 357,5 & 5,1 & 350,5 \\
\hline$P_{1}$ & 2,1 & 335,0 & 2,5 & 352,5 & 1,7 & 345,9 \\
\hline \multicolumn{7}{|c|}{ Semidiurnas } \\
\hline $\mathrm{N}_{2}$ & 7,4 & 340,9 & 4,1 & 291,1 & 7,2 & 283,0 \\
\hline $\mathrm{M}_{2}$ & 36,7 & 186,0 & 36,9 & 282,1 & 38,6 & 272,4 \\
\hline $\mathrm{L}_{2}$ & 4,9 & 28,8 & 3,2 & 251,7 & 2,4 & 293,2 \\
\hline $\mathrm{S}_{2}$ & 19,2 & 308,8 & 20,5 & 295,7 & 16,8 & 279,6 \\
\hline $\mathrm{K}_{2}$ & 5,2 & 318,8 & 5,6 & 296,8 & 4,6 & 280,2 \\
\hline \multicolumn{7}{|l|}{ Água rasa } \\
\hline $\mathrm{M}_{4}$ & 2,3 & 71,8 & 1,0 & 298,5 & 2,4 & 278,0 \\
\hline $\mathrm{MS}_{4}$ & 1,9 & 225,4 & - & - & 1,8 & 308,2 \\
\hline $\mathrm{MSN}_{2}$ & 5,7 & 325,4 & - & - & 1,9 & 184,5 \\
\hline $\mathrm{MNS}_{2}$ & - & - & 2,9 & 235,5 & 1,7 & 176,1 \\
\hline$M_{6}$ & 1,0 & 357,8 & 1,0 & 289,5 & 0,7 & 234,9 \\
\hline Soma & $\overline{102,9}$ & & 94,4 & & $\begin{array}{c}95,4 \\
\end{array}$ & \\
\hline
\end{tabular}

Tabela 5 - Parâmetros descritores da maré astronômica e o somatório das amplitudes e porcentagem das constantes harmônicas em todos os períodos selecionados (vide Tab. 1). 0 Número de Forma (NF) é adimensional, e os demais valores estão em centímetros.

\begin{tabular}{|c|c|c|c|c|c|c|c|c|c|c|}
\hline \multirow{3}{*}{ Períodos } & \multirow{3}{*}{$\begin{array}{c}\mathrm{NF} \\
\left(\mathrm{K}_{1}+\mathrm{O}_{1}\right) \\
\left(\mathrm{M}_{2}+\mathrm{S}_{2}\right)\end{array}$} & \multirow{3}{*}{$\begin{array}{c}\frac{h \mathrm{M}^{*}}{2,2} \\
\left(\mathrm{M}_{2}\right)\end{array}$} & \multirow{3}{*}{$\begin{array}{c}h \mathrm{~S}^{*} \\
2,0 \\
\left(\mathrm{M}_{2}+\mathrm{S}_{2}\right)\end{array}$} & \multirow{3}{*}{$\begin{array}{c}h Q^{*} \\
2,0 \\
\left(\mathrm{M}_{2}-\mathrm{S}_{2}\right)\end{array}$} & \multicolumn{6}{|c|}{$\sum$ espécies } \\
\hline & & & & & \multicolumn{2}{|c|}{$D^{*}$} & \multicolumn{2}{|c|}{$\mathrm{SD}^{*}$} & \multicolumn{2}{|c|}{$A R^{*}$} \\
\hline & & & & & (cm) & $(\%)$ & $(\mathrm{cm})$ & $(\%)$ & $(\mathrm{cm})$ & $(\%)$ \\
\hline $\mathrm{BD1}$ & 0,25 & 94,6 & 124,8 & 47,2 & 20,3 & 19,7 & 75,4 & 73,1 & 7,4 & 7,2 \\
\hline $\mathrm{BD} 2$ & 0,25 & 91,7 & 120,3 & 46,5 & 19,5 & 19,1 & 74,9 & 73,5 & 7,5 & 7,4 \\
\hline BD3 & 0,22 & 96,1 & 129,6 & 45,2 & 18,7 & 17,1 & 83,8 & 76,8 & 6,7 & 6,1 \\
\hline AD1 & 0,21 & 75,6 & 100,9 & 36,5 & 10,5 & 13,7 & 60,1 & 78,6 & 5,9 & 7,7 \\
\hline AD2 & 0,20 & 75,7 & 99,5 & 38,1 & 9,9 & 12,3 & 61,5 & 76,2 & 9,3 & 11,5 \\
\hline AD3 & 0,18 & 75,1 & 101,3 & 35,3 & 8,5 & 10,7 & 63,5 & 79,9 & 7,5 & 9,4 \\
\hline MM1 & 0,27 & 80,7 & 111,8 & 35,0 & 18,6 & 18,1 & 73,4 & 71,3 & 10,9 & $\overline{10,6}$ \\
\hline MM2 & 0,26 & 81,2 & 114,8 & 32,8 & 19,2 & 20,3 & 70,3 & 74,5 & 4,9 & 5,2 \\
\hline MM3 & 0,23 & 84,9 & 110,8 & 43,6 & 17,3 & 18,1 & 69,6 & 73,0 & 8,5 & 8,9 \\
\hline
\end{tabular}

${ }^{*} h \mathrm{M}=$ altura média; $h \mathrm{~S}=$ altura de sizígia; $h \mathrm{Q}=$ altura de quadratura; $\mathrm{D}=$ Diurnas; $\mathrm{SD}=$ Semidiurnas; $\mathrm{AR}=$ Águas Rasas . 

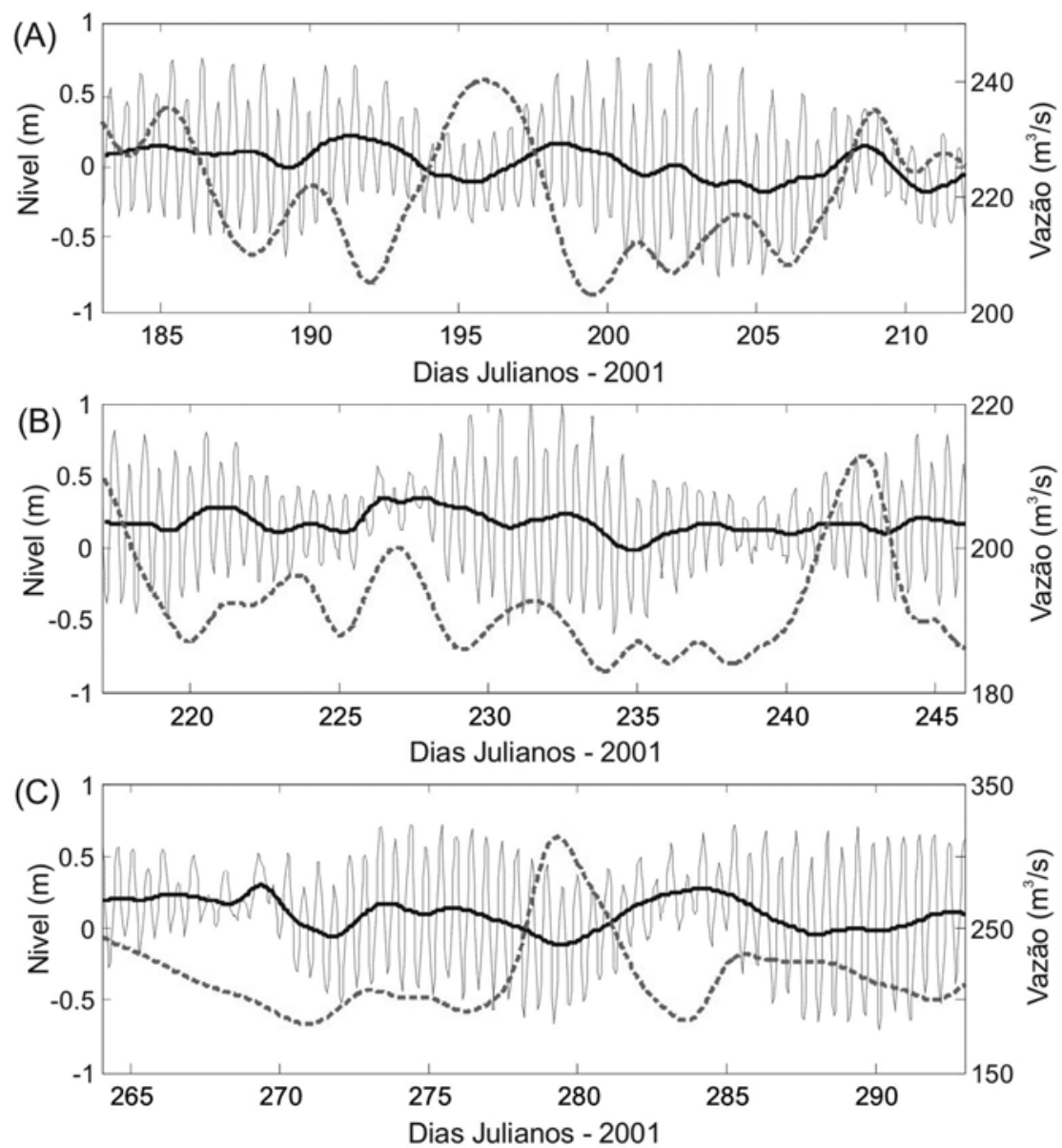

Figura 4 - Séries temporais de nível de água (linha cheia) e vazão (linha tracejada) dos períodos selecionados para caracterizar condição de baixa descarga e maré do rio Paraíba do Sul com maré meteorológica. A: MM1; B: MM2; C: MM3. Detalhes na Tabela 1. A linha preta em negrito representa o nível da água em freqüência submareal.

devida, principalmente, à co-oscilação da maré astronômica (sizígia e quadratura), a menos que outros eventos ocorram na costa, como a maré meteorológica.

\section{Períodos de alta descarga}

Onze constituintes harmônicas comuns foram obtidas em pelo menos dois períodos de alta descarga. Cada constituinte é descrito pela sua amplitude e fase, e, estão expressas na Tabela 3. Dentre elas, apenas duas espécies diurnas são comuns aos três períodos $\left(O_{1}\right.$ e $\left.K_{1}\right)$, cinco espécies semidiurnas e quatro de águas rasas. A altura média da maré encontrada nos três períodos foi de 75,6; 75,7 e 75,1 cm, atingindo valores médios nas preamares de sizígia de 100,9; 99,5 e 101,3 cm e durante os períodos de baixa-mares de quadratura 36,$5 ; 38,1$ e $35,3 \mathrm{~cm}$, respectivamente. A região pode ser caracterizada por micro-marés, pois a altura máxima da maré em todos os períodos foi menor que $2 \mathrm{~m}$. Os Números de Forma encontrados para os três períodos foram iguais a 0,21; 0,20 e 0,18 (Tab. 5) e são inferiores aos encontrados para o período de baixa descarga. Isto se deve a uma diminuição das amplitudes diurnas no somatório, com isso as espécies semidiurnas se tornam mais evidenciadas no baixo estuário. As constantes de espécies diurnas representam cerca de 13,7; 12,3 e 10,7\% do somatório das amplitudes. As constantes de espécies semidiurnas são responsáveis por 78,6; 76,2 e $79,9 \%$ da energia de maré, sendo que os 7,7; 11,5 e 9,4\% restantes são devido às constantes de água rasa, respectivamente para os períodos 1,2 e 3 .

As espécies diurnas foram menos energéticas no período de alta descarga do que aquelas encontradas com a vazão baixa, enquanto que as constantes semidiurnas, embora com valores individuais menores foram mais contribuintes para o somatório total 


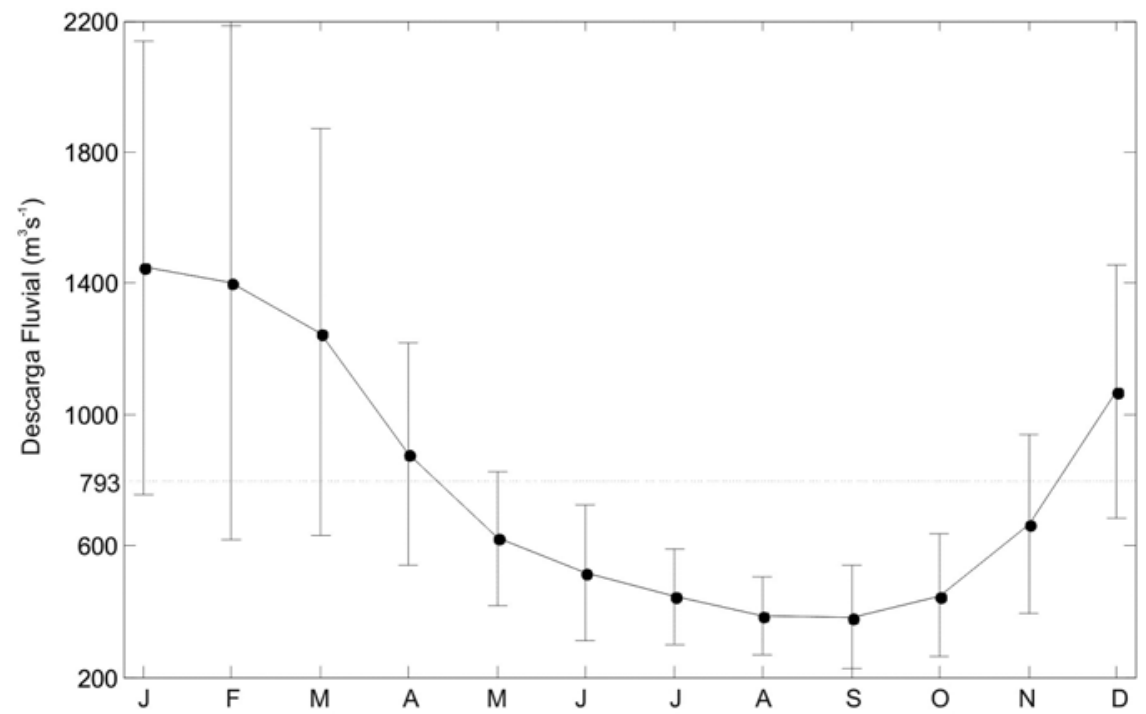

Figura 5 - Variação anual da descarga fluvial mensal média com respectivo desvio padrão, a partir de dados entre 1936 e 2006.
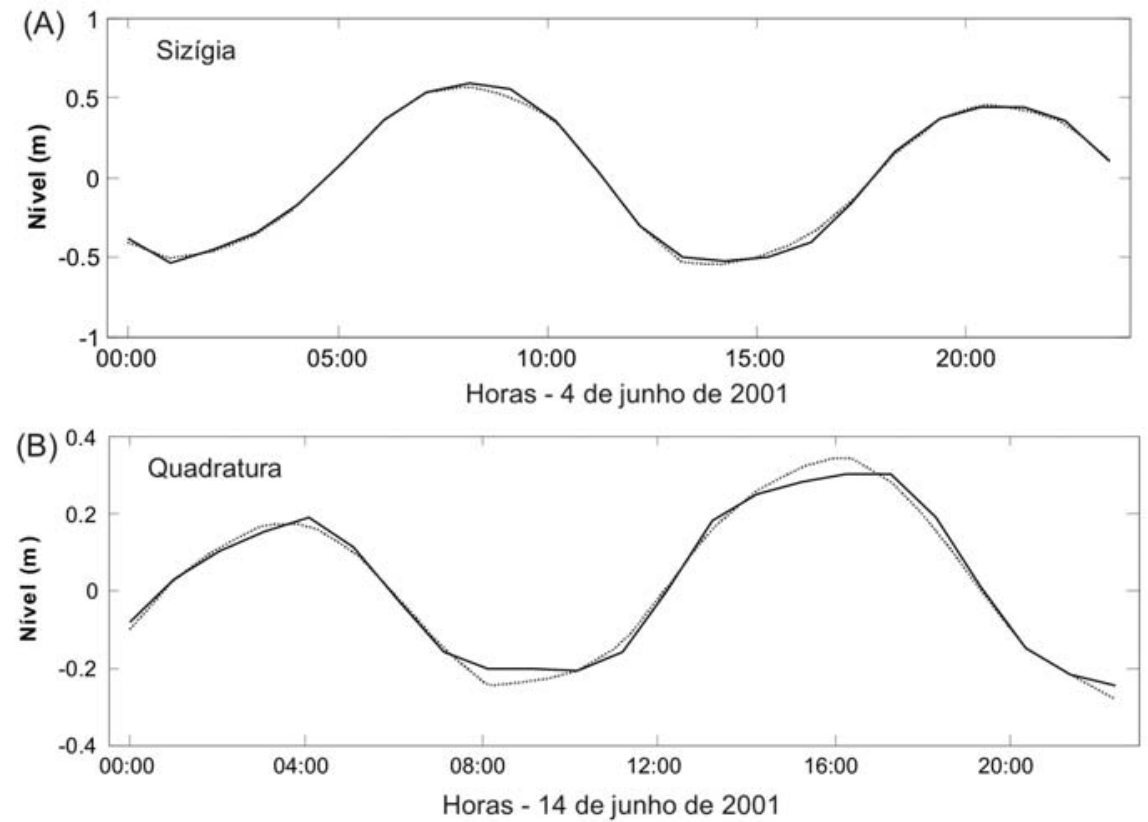

Figura 6 - Períodos de 24 horas de nível da água observado (linha cheia) e maré astronômica prevista (linha pontilhada) para condição de maré de sizígia (A) e quadratura (B).

das amplitudes da maré no baixo estuário. As componentes de águas rasas tiveram as amplitudes maiores, embora tivesse um composto a menos, a espécie de água rasa foi mais energética nos períodos de alta descarga.

Nos três períodos analisados as principais constantes lunar, $\mathrm{M}_{2}$ e solar, $\mathrm{S}_{2}$ foram as mais energéticas, apresentando a primeira 34,3; 34,4 e 34,1 cm e a segunda 16,1; 15,4 e 16,5 cm. Quando comparadas com as constantes do período de baixa des- carga nota-se uma redução na amplitude em torno de 22\% para $\mathrm{M}_{2}$ e $20 \%$ para $\mathrm{S}_{2}$. Com a alta descarga, a co-oscilação da maré astronômica teve suas amplitudes consideravelmente reduzidas ao penetrar no estuário, tanto na sizígia como na quadratura. 0 efeito da descarga na atenuação da curva de co-oscilação da maré é exemplificado nas Figuras 7 e 8 para períodos de sizígia e quadratura, respectivamente. Na Figura 7 a amplitude prevista seria de 0,71 cm na preamar de sizígia no dia 03/01/02 às 0h, 
entretanto, a amplitude observada foi de $0,31 \mathrm{~cm}$, ou seja, diminuiu em $40,0 \mathrm{~cm}$, 0 que representa uma redução de $56 \%$. Ocorre também uma assimetria da onda de co-oscilação da maré, com 0 tempo de subida superior à descida em até $2 \mathrm{~h}$. Na Figura 8 as variações sinópticas chegaram a ser $25,0 \mathrm{~cm}$ no dia 06/02/02 às $17 \mathrm{~h}$, medindo $0,12 \mathrm{~cm}$, enquanto 0 previsto seria $0,37 \mathrm{~cm}$. Isto representa uma redução de $68 \%$ na amplitude da maré de quadratura. Na quadratura, 0 intervalo de tempo de descida da maré foi menor que 0 da sizígia chegando a 4h, e em seguida levou 7h para atingir a preamar. As assimetrias geradas tanto na quadradura como na maré de sizígia sugerem que a corrente de vazante é mais rápida e, portanto, mais intensa que a corrente de maré de enchente, sugerindo assim, que o sistema é dominado por correntes de maré de vazante. Este fato pode ser corroborado com valores encontrados através da relação de fase entre os constituintes $M_{2}$ e $M_{4}$, pois os valores encontrados para os três períodos foram iguais a 292,07 ; $258,15^{\circ}$ e $259,22^{\circ}$, de forma semelhante aos três períodos analisados em baixa descarga, o sistema pode ser caracterizado por domínio de vazante. A razão das amplitudes $A \mathrm{M}_{4} / A \mathrm{M}_{2}$ obtidas foram 0,06 para os períodos 1 e 3, e 0,08 para o período 2. Estes valores indicam uma maior distorção da curva de co-oscilação da maré do que nos períodos de baixa descarga fluvial.

\section{Períodos de baixa descarga com eventos meteorológicos}

Nos períodos de baixa descarga em que foram observadas oscilações significativas do nível do mar não explicadas pela descarga fluvial, sendo assim atribuídas a efeitos meteorológicos, pode-se observar uma diminuição das amplitudes de alguns constituintes diurnos e também semidiurnos ( Como o $\mathrm{M}_{2}$ ) em até $16 \%$ quando comparamos com os períodos de baixa descarga em que não ocorreram eventos meteorológicos, contudo, 0 efeito da alta descarga foi ainda maior sobre as constantes, pois a queda foi de $22 \%$ para $0 \mathrm{M}_{2}$ (Tab. 4). Entretanto, para as componentes de águas rasas houve um ligeiro aumento, com 0 aparecimento do composto $\mathrm{MNS}_{2}$ em dois períodos. Esta queda nas amplitudes, e a distorção da onda de maré podem ser observadas nas Figura 8. No período de quadratura e início de sizígia existiu uma forte distorção na onda de maré, promovendo um atraso na fase, com o pico de enchente acontecendo mais tarde e o período de enchente mais curto que 0 de vazante ( $\sim 5$ e 8 h). Na sizígia este intervalo de duração ficou em torno de 4 a 5 horas na subida e de 7 a 8 h na descida, ou seja, uma diferença de 3 horas. Isto significa que a força da corrente de maré de enchente é maior que a de vazante, neste momento o estuário pode vir a ser um importador de propriedades do oceano, sendo caracterizado como dominado por correntes de marés de enchente. Entretanto, este efeito deve durar apenas poucos dias, mas pode ser fundamental para circulação no estuário. 0 mesmo não ocorre para a relação de fase entre $\mathrm{M}_{2}$ e $\mathrm{M}_{4}$, que para os três períodos foi de $300,2^{\circ} ; 265,7^{\circ}$ e $266,8^{\circ}$, o que caracteriza o sistema como um todo, como dominado por marés de vazante na maior parte do tempo, assim como em baixa e alta descarga. Isto provavelmente é devido ao curto período de maré meteorológica existente, num intervalo de 29 dias, ou seja, a maior parte do tempo não está ocorrendo maré meteorológica na costa.

A razão $A \mathrm{M}_{4} / A \mathrm{M}_{2}$ obtida para os períodos 1 e 3 foi de 0,06 e no período 2 foi de 0,03 . Este indicador de distorção mostra que eventos de maré meteorológica costeira causam uma maior deformação da co-oscilação de maré do que seria em períodos de baixa descarga fluvial, quando há somente 0 efeito de fricção e da morfologia do estuário. Através do Número de Forma encontrado, 0,27; 0,26 e 0,23; podemos caracterizar 0 regime de maré, assim como na baixa descarga, como sendo do tipo misto, com predominância semidiurna, com desigualdades de altura entre os ciclos de maré consecutivos. A altura média da maré astronômica ficou entre 80 e $85 \mathrm{~cm}$, sendo a máxima de sizígia 114,8 no MM2 e de quadratura 43,6 no MM3 (Tab. 5).

Assim como nos outros períodos os constituintes semidiurnos de maré foram os mais energéticos, entretanto as componentes de águas rasas foram menos contribuintes para 0 nível de co-oscilação da maré do que em períodos de baixa descarga, porém foram mais representativas para 0 somatório total do que em períodos de altas descargas. Os componentes e compostos gerados em águas rasas são os principais indicadores de distorção da onda de maré.

\section{DISCUSSÃO}

Segundo Nichols \& Biggs (1985), as marés astronômicas sofrem processos de distorção ao entrarem em sistemas restritos devido aos efeitos de fricção com o fundo e constrição das margens, podendo haver diminuição (hiposíncrono), manutenção (síncrono) ou amplificação (hipersíncrono) da altura de marés. Em estuários do tipo frente deltaica (e.g. Fairbridge, 1980), geralmente estreitos e rasos, é esperado que os efeitos friccionais prevaleçam $\mathrm{e}$ ocorra a gradual dissipação da energia de maré. Contudo, além dos efeitos friccionais com o fundo há também os efeitos não lineares relacionados com a descarga fluvial com sentido oposto da propagação da maré (Godin, 1991). Uma conseqüência destes efeitos é a produção de assimetrias da maré, as quais apresentarão efeitos importantes sobre 0 balanço de materiais em 


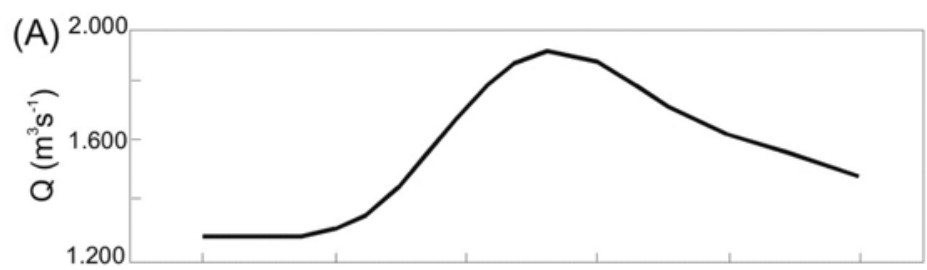

(B)
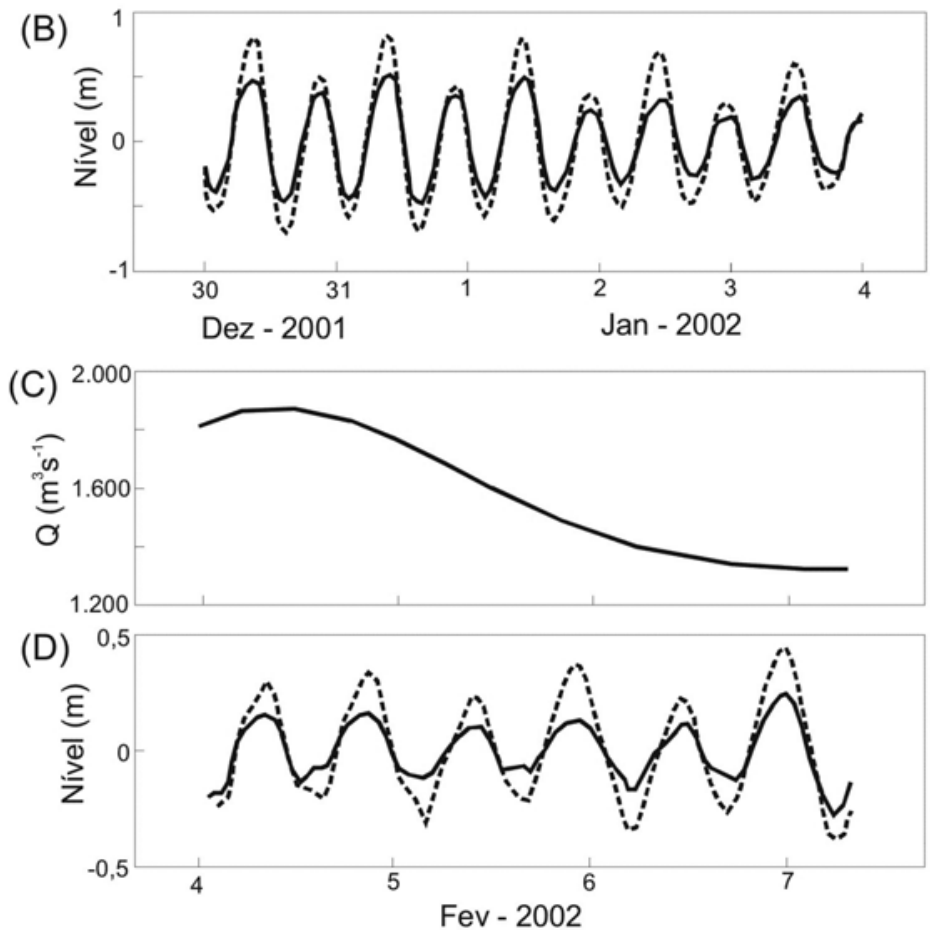

Figura 7 - Períodos de alguns dias para demonstrar 0 efeito da alta descarga fluvial sobre 0 nível da água do estuário, em períodos de maré de sizígia ( $A$ e B) e quadratura (C e D). (A e C): descarga fluvial; (B e D): nível da água observado (linha cheia) e maré astronômica predita (linha tracejada).

estuários (Dyer, 1995), o que torna alguns ambientes exportadores e outros em importadores (e.g. Speer \& Aubrey, 1985; Medeiros \& Kjerfve, 1993; Schettini \& Carvalho, 1999; Schettini et al., 2000; Shuttleworth et al., 2005; Schettini \& Toldo Jr, 2006; Schettini et al., 2006). A condição de exportador de sedimentos e nutrientes do estuário do RPS foi verificada por Gonçalves (2004) e Krüger et al. (2003), através da coleta dos dados de vazão, nível de maré, salinidade, material particulado em suspensão (MPS), assim como outros compostos no estuário durante um período de baixa descarga, tanto em condição de quadratura quanto sizígia.

As assimetrias no tempo de subida e de descida da maré foram maiores na quadratura do que na sizígia. Esse comportamento era esperado, uma vez que na quadratura as amplitudes de maré são menores, tornando relativamente maior o papel da descarga. A assimetria é muito importante no manejo do estuário, particularmente em relação ao transporte de sedimen- tos, dispersão de poluentes da coluna de água e numa escala de tempo maior, na estabilidade do estuário, uma vez que, no decorrer do ciclo de maré, há um transporte estuário acima (enchente) e abaixo (vazante) (Speer \& Aubrey, 1985; Miranda et al., 2002). Se os intervalos de tempo de enchente e vazante são diferentes, segue-se pelo princípio de conservação de volume que no evento de menor duração, como na maré de vazante do estuário do RPS, a velocidade do movimento será mais intensa. Como conseqüência, 0 transporte de sedimentos em suspensão será maior na vazante do que na enchente, e, portanto, o estuário é dominado pela maré de vazante, sendo um exportador de sedimentos. Isto se confirma pela relação de fase entre $\mathrm{M}_{2}$ e $\mathrm{M}_{4}$ encontrada para este período.

Os eventos de maré meteorológica causaram fortes distorções na onda de co-oscilação da maré, promovendo um atraso na fase, com o pico de enchente acontecendo mais tarde e o período 

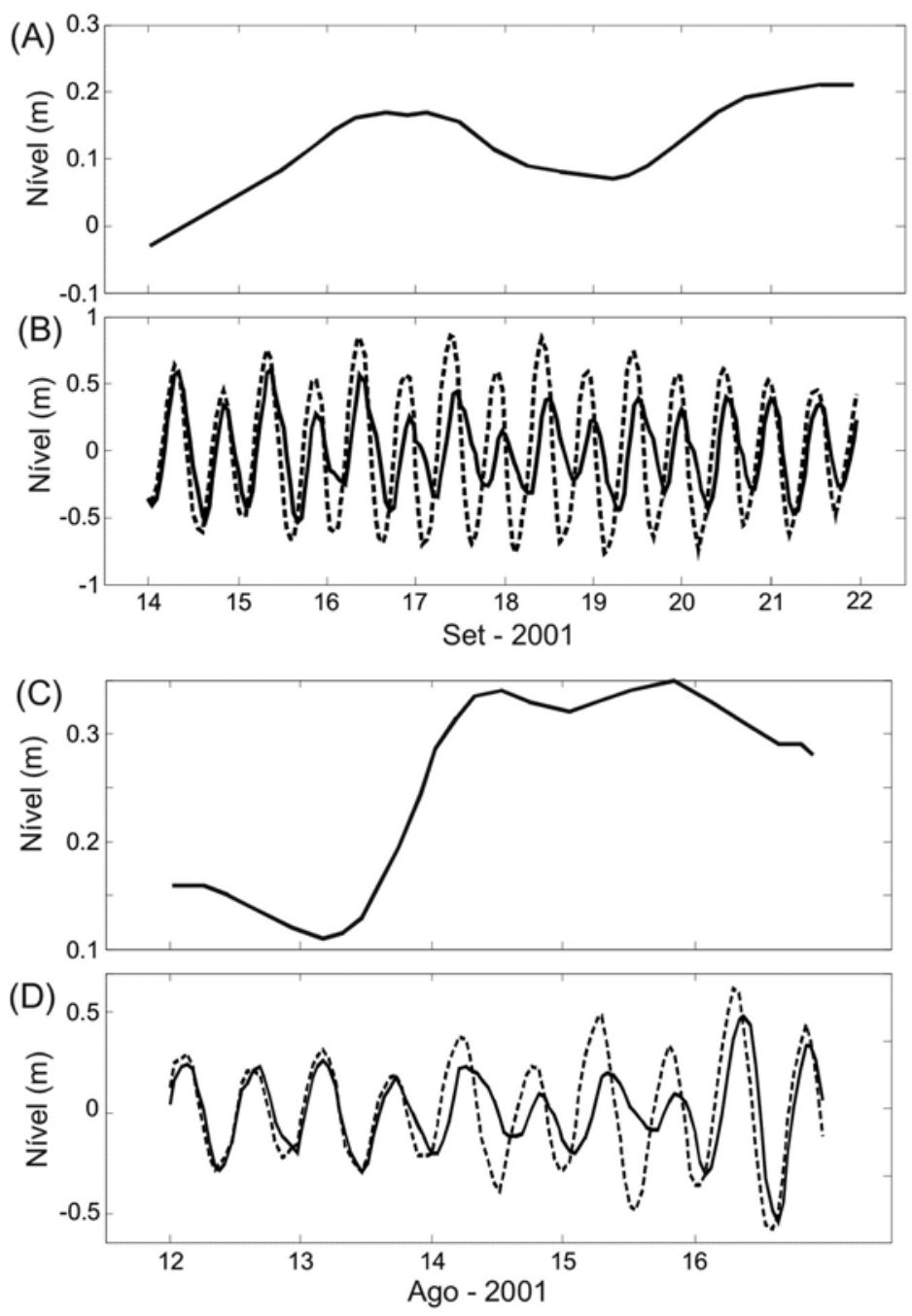

Figura 8 - Períodos de alguns dias para demonstrar o efeito de marés meteorológicas sobre o nível da água do estuário, em períodos de sizígia ( $A$ e B) e quadratura (C e D). ( $A$ e C): variação do nível da água em freqüência submareal; (B e D): nível da água observado (linha cheia) e maré astronômica predita (linha tracejada).

de enchente mais curto que o de vazante ( $\sim 5$ e 8 h). Eventos ocorridos tanto em períodos de quadratura como em sizígia causaram estas distorções na onda de maré, promovendo um atraso na fase, e redução das amplitudes. Estes resultados indicam que nestes momentos a força da corrente de enchente é maior que a de vazante. Nestes casos, o estuário pode vir a ser um importador de propriedades da plataforma, sendo caracterizado como dominado por marés de enchente. Entretanto, este efeito deve durar apenas poucos dias, durante a maré meteorológica, mas pode ser fundamental para circulação de água, sedimentos e fitoplâncton no estuário.

As componentes de águas rasas foram menos contribuintes para o nível de maré do que em períodos de baixa descarga, porém foram mais representativas para o somatório total do que em períodos de altas descargas. Os componentes e compostos gerados em águas rasas são os principais indicadores de distorção da onda de maré (Pugh, 2004). Segundo George (1995), os efeitos de um aumento da descarga fluvial no estuário são: aumento tanto da preamar como da baixa-mar, porém 0 aumento da preamar é bem inferior à baixa-mar, uma vez que a largura das margens do estuário é capaz de acomodar mais facilmente 0 excesso de água doce na preamar; a velocidade da corrente de vazante aumenta, enquanto na enchente é diminuída; todos os limites são deslocados mais para jusante, como o limite de influência da co-oscilação da maré. Sendo assim, a maior parte do estuário está operando como um rio, sem efeitos da maré. 
No presente estudo, podemos verificar que apenas grandes valores de descarga $\left(>1.500 \mathrm{~m}^{3} . \mathrm{s}^{-1}\right)$ fazem subir os níveis tanto na baixa-mar quanto na preamar, porém nesta última bem menos que a primeira, conforme observado por George (1995). Enquanto que picos abaixo deste valor, não interferem de forma significativa para aumentar o nível de água do baixo estuário e em baixas descargas o nível é totalmente influenciado pela maré e eventos que ocorrem no oceano.

\section{CONCLUSÕES}

A variabilidade do nível da água no baixo estuário do RPS é principalmente devida à co-oscilação da maré astronômica, a qual contabiliza cerca de $84 \%$ da variância. Em períodos de baixa vazão, as oscilações do nível de água do baixo estuário do RPS ocorrem exclusivamente em função da co-oscilação da maré astronômica, a menos que ocorram eventos de maré meteorológica. Não foi possível observar grandes deformações da onda de maré causadas pela vazão, exceto na quadratura, quando houveram ligeiras deformações atribuídas ao efeito friccional sobre a propagação da onda.

Em períodos de alta descarga (acima da média histórica $796 \mathrm{~m}^{3} . \mathrm{s}^{-1}$ ), o nível de água do baixo estuário se encontra dominado pela co-oscilação, tendo a descarga fluvial uma influência maior nos níveis da baixa-mar do que nos níveis da preamar e eventos de maré meteorológica podem aumentar 0 nível como podem abaixá-lo. Já em períodos de altíssima descarga (>1500 $\mathrm{m}^{3} \cdot \mathrm{s}^{-1}$ ) 0 nível da água é influenciado tanto da descarga fluvial quanto da maré nas oscilações do nível e a descarga aumenta 0 nível das baixa-mares, enquanto que a maré é responsável pela altura das preamares.

Com relação aos efeitos sobre a co-oscilação da maré astronômica temos que em períodos de baixa descarga quase não houve modificação na onda de maré, ocorrendo apenas uma pequena assimetria no sentido de vazante. Em períodos de alta descarga houve fortes distorções na onda de maré em períodos de quadratura e uma atenuação considerável nas amplitudes tanto de sizígia como de quadratura, com assimetrias no sentido de vazante corroboradas pela relação de fase entre $\mathrm{M}_{2}$ e $\mathrm{M}_{4}$.

\section{AGRADECIMENTOS}

0 presente trabalho foi realizado com 0 apoio financeiro do Instituto do Milênio Estuários (CNPq 420050/2005-1); FAPERJ (E-26/170.368/1999-APQ1) e Instituto Nacional de Ciência e Tecnologia de Transferência de Materiais Continente-Oceano (INCTTMCOcean) - (CNPq-Proc. No. 573.601/2008-9). Agradecemos às críticas dos revisores anônimos pela contribuição na melhoria do manuscrito. Micaela Nicolite agradece à FAPERJ/ UENF, pela concessão de bolsa de mestrado. Bolsas CNPq/PQ 306603/2006-3 e 306217/2007-4.

\section{REFERÊNCIAS}

CARNEIRO MER. 1998. Origem, transporte e destino da matéria orgânica no estuário do Rio Paraíba do Sul. Tese de Doutorado em Geociências Niterói, Rio de Janeiro: Universidade Federal Fluminense, 210 p.

COSTA G. 1994. Caracterização histórica, geomorfológica e hidráulica do estuário do Rio Paraíba do Sul. Dissertação de mestrado, COPPE, Universidade Federal do Rio de Janeiro, $97 \mathrm{p}$.

DYER KR. 1995. Sediment transport processes in estuaries. In: PERILLO GME (Ed.). Geomorphology and sedimentology of estuaries. New York, Elsevier, pp. 423-449.

DYER KR. 1997. Estuaries: A Physical Introduction. 2 ed. New Jersey: John Wiley \& Sons. $195 \mathrm{p}$.

FAIRBRIDGE RW. 1980. The estuary: its definition and geodynamic cycle. In: OLAUSSON E \& CATO I (Eds.). Chemistry and biogeochemistry of estuaries. New York, John Wiley \& Sons, pp. 1-35.

FRANCO AS. 1988. Tides - Fundamentals, Analysis and Prediction. 2 ed., Fundação Centro Tecnológico de Hidráulica (FCTH), São Paulo, Brasil. $249 \mathrm{p}$.

GEORGE KL. 1995. Tides for marine studies. University of Plymouth. Institute of Marine Science (2 ed.). $180 \mathrm{p}$.

GODIN G. 1991. Frictional effects in river tides. In: PARKER BB (Ed.). Tidal hydrodynamics. New York, John Wiley \& Sons, pp. 379-401.

GONÇALVES GM. 2004. Dinâmica e fluxo de metais pesados nas frações particulada e dissolvida no estuário do Rio Paráíba do Sul, RJ, sob diferentes condições de maré e vazão fluvial. Dissertação de mestrado. Centro de Biociências, Universidade Estadual do Norte Fluminense Darcy Ribeiro, $110 \mathrm{p}$.

KRÜGER GCT, CARVALHO CEV, FERREIRA AG, GONÇALVES EG, TRUCCOLO EC \& SCHETTINI CAF. 2003. Dinâmica de carbono orgânico dissolvido no estuário do Rio Paraíba do Sul, RJ, sob diferentes condições de maré e descarga fluvial. Atlântica, 25(1): 27-33.

MAO Q, SHIA P, YIN K, GAN J \& QI Y. 2004. Tides and tidal currents in the Pearl River Estuary. Continental Shelf Research, 24: 1797-1808.

MARTIN L, SUGUIO K, FLEXOR JM, TESSLER M \& EICHLER B. 1984. Significado geológico das variações dos graus de arredondamento das areias holocênicas da planície costeira do rio Paraíba do Sul (RJ). Anais do XXXIII Congresso Brasileiro de Geologia. Rio de Janeiro, (1) 119132.

MEDEIROS C \& KJERFVE B. 1993. Hydrology of a Tropical Estuarine System: Itamaracá, Brazil. Estuarine, Coastal and Shelf Science, 36: $495-515$. 
MIRANDA LB, CASTRO BM \& KJERFVE B. 2002. Princípios de Oceanografia Física de Estuários. São Paulo: Edusp. 424 p.

NICHOLS MM \& BIGGS RB. 1985. Estuaries. In: DAVIS RA (Ed.). Coastal Sedimentary Environments. Berlin: Springer-Verlag. pp. 77-186.

PARKER BB. 1991. The relative importance of the various nonlinear mechanisms in a wide range of tidal interactions (Review). In: PARKER BB (Ed.). Tidal Hydrodynamics. N.Y. John Wiley \& Sons. pp. 125-152.

PUGH D. 2004. Changing sea levels: Effects of Tides, Weather and Climate. Cambridge: Univ. Press. 265 p.

RIBEIRO GP \& ROSAS R0. 2006. Mapeamento digital de Erosão em Atafona e Progradação em Grussaí, São João da Barra (RJ). Geodésia Online, v. 2, p. 1-2, <http://geodesia.ufsc.br/geodesia-online/arquivo/ 2006/02.2/gp-2006-res.htm >; Série: 2006; ISSN/ISBN: 1415111.

SCHETTINI CAF \& CARVALHO JLB. 1999. Caracterização hidrodinâmica do estuário do Rio Cubatão, Joinville. Notas Téc. Facimar, 3: 87-97.

SCHETTINI CAF \& TOLDO JR EE. 2006. Fine sediment transport modes in the Itajaí-Açu estuary, Southern Brazil. Journal of Coastal Research 39(SI): 515-519.

SCHETTINI CAF, PEREIRA FILHO J \& SPILLERE L. 2000. Caracterização oceanográfica e biogeoquímica dos estuários dos Rios Tavares e Defuntos, Reserva extrativista de Pirajubaé, Florianópolis, SC. Notas Téc. Facimar, 4: 11-28.
SCHETTINI CAF, RICKLEFS K, TRUCCOLO EC \& GOLBIG V. 2006. Synoptic hydrography of a highly stratified estuary. Ocean Dynamics, doi: 10.1007/s10236-006-0066-1.

SCHUREMAN P. 1971. Manual of harmonic analysis and prediction of tides. U.S. Department of Commerce, Coast and Geodetic Survey, Special Publication No. 98, U.S. Government Printing Office, Washington. $316 \mathrm{pp}$.

SHUTTLEWORTH B, WOIDT A, PAPARELLA T, HERBIG $S \&$ WALKER D. 2005. The dynamic behaviour of a river-dominated tidal inlet, River Murray, Australia. Estuarine, Coastal and Shelf Science, 64: 645-657.

SPEER PE \& AUBREY DG. 1985. A study of non-linear tidal propagation in shallow inlet/estuarine systems. Part II: Theory. Estuarine, Coastal and Shelf Science, 21: 207-224.

TRUCCOLO EC. 2005. Hidrodinâmica de Estuários em Freqüência Mareal e Submareal. Monografia. Doutorado em Geociências. Universidade Federal do Rio Grande do Sul, 101 p.

TRUCCOLO EC \& SCHETTINI CAF. 1999. Marés Astronômicas na Baía da Babitonga, SC. Notas Téc. Facimar, 3: 57-66.

TRUCCOLO EC, FRANCO D \& SCHETTINI CAF. 2006. The Low Frequency Sea Level Oscillations in the Northern Coast of Santa Catarina, Brazil. Journal of Coastal Research, 39(SI): 547-552.

\section{NOTAS SOBRE OS AUTORES}

Micaela Nicolite. Bióloga formada pela Universidade Estadual do Norte Fluminense, em 2004; Mestre em Ecologia e Recursos Naturais pela mesma universidade em 2007. Atualmente é tutora do Curso de Ciências Biológicas do CEDERJ e bolsista de Apoio Técnico pela Fundação Estadual do Norte Fluminense - FENORTE. Áreas de interesse: ecologia de ecossistemas, hidrodinâmica estuarina.

Eliane Cristina Truccolo. Oceanógrafa formada pela Fundação Universidade do Rio Grande (FURG) em 1993; Mestre em Engenharia Ambiental pela Universidade Federal de Santa Catarina (UFSC) em 1998; Doutoranda em Geociências pela Universidade Federal do Rio Grande do Sul (UFRGS). Docente e pesquisadora no Centro de Ciências Tecnológicas da Terra e do Mar da Universidade do Vale do Itajaí (CTTMar/UNIVALI) entre 1996 e 2009. Área de interesse: oceanografia física estuarina e costeira; interações oceano-atmosfera.

Carlos Augusto França Schettini. Oceanógrafo formado pela Fundação Universidade do Rio Grande (FURG) em 1991; Mestre em Geociências pela Universidade Federal Fluminense (UFF) em 1994; Doutor em Geociências pela Universidade Federal do Rio Grande do Sul (UFRGS) em 2001. Docente e pesquisador do Centro de Ciências Tecnológicas da Terra e do Mar da Universidade do Vale do Itajaí (CTTMar/UNIVALI) entre 1994 e 2009, na graduação e pós-graduação; Professor colaborador no Programa de Pós-Graduação em Geociências (PPGGEO) da UFRGS. Atualmente é Professor no Instituto de Ciências do Mar da Universidade Federal do Ceará (LABOMAR/UFC). Áreas de interesse: oceanografia física estuarina e costeira.

Carlos Eduardo Veiga de Carvalho. Graduado em Ciências Biológicas pela Universidade Federal do Rio de Janeiro (1989), mestrado em Geociências (Geoquímica) pela Universidade Federal Fluminense (1992) e doutorado em Geociências (Geoquímica) pela Universidade Federal Fluminense (1997). Atualmente é pesquisador do Conselho Nacional de Desenvolvimento Científico e Tecnológico e Professor Associado I da Universidade Estadual do Norte Fluminense Darcy Ribeiro. Tem experiência na área de Geociências, com ênfase em Geoquímica Ambiental, atuando principalmente nos seguintes temas: metais pesados, peixe, contaminação, mercúrio e lagoas. 